Riga, Latvia, November 20, 2020

\title{
SOCIOLOGICAL SCIENCES
}

\section{PRIVATE LIFE ORGANIZATION FORMS CHANGE \\ IN THE SOCIAL INSTITUTE OF FAMILY TRANSFORMATION CONTEXT}

\author{
Svitlana Vakulenko ${ }^{1}$ \\ Tetyana Yakovenko ${ }^{2}$
}

DOI: https://doi.org/10.30525/978-9934-26-002-5-36

In the last few decades, statistical data and sociological research show significant changes in the family as a social institution. These trends relate to the global socio-economic and socio-cultural processes, as well as to the specificities of the transformation processes taking place in Ukrainian society.

Nowadays in many countries around the world, the various forms of the private life organization appear, replacing one marital model domination, i.e., there occurs the pluralization of family life forms. The scale and factors of this pluralization come as the object of research in sociology. It is explained as the direct result of both current technical and economic development of society and the deeper reasons related to the values' influence on the families formation and functioning.

In Western European societies and the United States, the determining effect on the condition and development of the family social institution since the 1960s is made by social factors. They are the radical changes in the role and place of women in socio-economic life; the need for self-realization in extra-family spheres activities (especially for women); liberalization of public morality, beginning to tolerate divorce, premarital sex, non-registered marital partnerships, non-marital births. Until recently, the normative type of family and household was only the traditional family - a married couple with children. Other types of families or individuals, who had no family at all, were considered social norm violators.

The experience of the developed Western countries shows that the erosion of traditional family forms can develop on the background of intensive economic growth and the improvement of the population life standard and quality. The family, in the vast majority of cases, is no longer a production unit that provides employment for all its members. Adult family members are

\footnotetext{
${ }^{1}$ V.N. Karazin Kharkiv National University, Ukraine

${ }^{2}$ V.N. Karazin Kharkiv National University, Ukraine
} 
engaged in professional activities, usually outside the home, and the family business has survived to a very limited extent in agriculture and services. In societies with a market-based economy, traditional ties between family members and types of socioeconomic dependence are transforming. The social protection systems improvement, public and private health, and pension programs development can work towards weakening of the traditional family preferring lifestyle. The formation of health care, education, social insurance, the banking system has made it possible to meet such needs as assistance in case of illness and old age, the financial credits receiving, vocational training, etc., from other institutions. They are accessed on an individual basis, i.e. personal social security practically does not depend on the presence or absence of a family. Taking care of the sick, unemployed, the elderly, etc., society seems to devalue the role of the family in these activities. Thus, it is possible to talk about competing norms of institutions, when individuals and families deviate from traditional family norms to adapt to changes.

Market relations, inherent in the production and financial spheres, penetrate the sphere of marital and family relations. As a result, when comparing the effectiveness of the two areas - employment and family business - in terms of personal income, it turns out that investing in education, health, career growth of an individual brings much more income in money equivalent, so they are more profitable than spending time and money on family and children. Parentsinvestors are losing both in the short and long term. After all, caring for a child requires a significant reduction in working hours, up to complete abandonment from work for several years, for one parent, and limited opportunities for professional and geographical mobility for the other. That is, it turns out that for functioning in the labor market properly, free time should be distributed very efficiently, excluding the cost of activities that do not lead to an increase in income, including the children's birth and upbringing.

From this perspective, the traditional family inevitably loses in comparison with other forms of private life organizations that seem more flexible and more adapted to the postmodern society conditions. In the extremely individualized society, the traditional family appears unstable, and nontraditional forms of household organization, on the contrary, show high viability and become habitual. The wide use of such forms happens due to their correspondence to the needs of contemporary society. Therefore, it is hardly correct to consider single-person households or single-parent families simply to be the traditional family form crisis result, as just fragments of the «normal». These are independent, stable forms of private life organization that correspond to modern social conditions.

The statement about the actual changes taking place with the family reflects only one side of the considered processes. There is an obligation to look at them 
from a subjective point of view, i.e., to find out to what extent these changes and new trends are internalized by the subjects and have received value recognition. Both aspects of the family are linked inextricably: family behavior influences value choices and the latter influence the family. During internalization, values not only gain recognition and become norms of subjects' behavior, but can also become incentives for further behavior. That is, values and their normative implementation play an extremely important role in the lives of individuals, and their changes in one or another way affect the course of life and, in particular, the state of social institutions of marriage and family.

An important distinguishing feature of the traditional family is the abiding by the values that can be called «family-centered»: the priority of living within the family, the birth of children and their upbringing by both parents, the higher importance of social and the institution of family's stability compared with the personal happiness and interests of an individual. The diversity of family life models also involves a revision of these values, at least of their being obligatory for everyone. In modern society, everyone has the right to a free and socially acceptable choice between formal marriage and partnership, childhood and childlessness, in-family and out-family lifestyles, all directly relating to the field of human rights. Thus, the value of personal autonomy is directly related to the individual needs recognition, allowance to have interests outside the family, the individualistic values predominance in Western societies, and their further spreading.

The multifaceted understanding of autonomy is one of the core elements of postmodernism. The family is no longer perceived as a source of protection from economic instability only and becomes a source of psychological support, a way to organize leisure, fulfill the emotional needs of the individual, the need for close relationships, and personal happiness. Marital relations are gradually turning into the psychological value that generates the so-called «marital» model of the family spreading. The description of its main features is presented in detail in the works of S. Golod [1, p. 117]:

1) mandatory childbirth planning;

2) principal minor fertility;

3) spouses prefer personal values (autonomy);

4) the monopoly for sexuality control and procreation loss by the institution of marriage;

5) pluralism in family and marriage models.

This model has its undoubted advantages over the traditional family model, but at the same time, it is much less stable. On one hand, this family type provides the conditions for the realization of individual values by both men and women, adults, and children. On the other, strengthening of personal autonomy makes relationships between members of different sexes and generations more vulnerable 
and emotionally dependent. For example, the coincidence of the spouses' views on the autonomy border of each of them acquires special significance.

In modern conditions, the development of marital and family relations in Ukraine shows the same trends, which are observed in developed countries, but with slight specificity. In addition to the general patterns of marital and family relations development, during the period of independence the Ukrainian family's problems largely derived from the influence of the systemic socioeconomic crisis of the 1990ths, when the social institution of the family felt the deforming influence of the social and demographic crisis of the transition period.

However, regarding the long-term development prospects, the family should be recognized as a basic structure, the fundamental for society, because qualitative changes in all spheres of society are provided by individuals who adhere to relevant values, have a certain level of physical, intellectual, and moral development, and all these features are formed, first and mainly, by the family.

\section{References:}

1. Golod, S. I. (2003). Perspektivy monogamnoy semi: sravnitelnyy mezhkulturnyy analiz [Perspectives of a monogamous family: comparative intercultural analysis]. The Journal of Sociology and Social Anthropology, vol. VI, no. 2, pp. 106-119.

\section{THEORY OF GLOBAL NORTH AND GLOBAL SOUTH IN SOCIOLOGICAL PRACTICE}

\section{Kseniia Cherniak $^{1}$}

DOI: https://doi.org/10.30525/978-9934-26-002-5-37

Being open to multidisciplinary research, sociology often adapts approaches and theories from other scientific fields for the use in sociological practice. One of the recent theories that is not primarily mentioned as sociological but gets more and more popularity is the theory of Global North and Global South. Appeared first around 1970s-80s as a replacement of terms «First» and «Third World» in geopolitics and international relations, from the end of 1990s the theory has taken a steady place in sociological research.

In this regard, it becomes important to systematize the development and current usage of the theory in sociology, outline problems and possible directions of further research. Moreover, as theory only enters sociology, it is

${ }^{1}$ V. N. Karazin Kharkiv National University, Ukraine 